\title{
FINAL DA ERA TOKUGAWA E INÍCIO DA ERA MEIJI (1868) - O FASCÍNIO EUROPEU PELAS ARTES JAPONESAS
}

\section{Monica Setuyo Okamoto}

RESUMO: O texto trata da interação no mundo das artes que ocorreu entre Japão e França, durante a segunda metade do século XIX.

ABSTRACT: The text is on interaction in the world of art that occured between Japan and France, during the half second of XIX century.

PALAVRAS-CHAVE: Ukiyo-e, Impressionismo, Monet.

KEYWORDS: Ukiyo-e, Impressionism, Monet.

Os japoneses da era Tokugawa (1603-1868) tiveram uma certa liberdade de expressão e de recepção no campo artístico. Os pintores japoneses adotaram algumas técnicas ocidentais, dentre elas a perspectiva e a pintura a óleo. Por outro lado, foi constado um enorme entusiasmo europeu pela pintura e pelos objetos de decoração japoneses como o makie (pinturas em rolo), os objetos de laca e porcelanas. Mesmo diante das restrições do regime Tokugawa, a interação cultural entre Japão e o Ocidente ocorreu sutilmente através do mundo artístico japonês.

A arte japonesa atingiu, na metade do século XIX, projeção e reconhecimento internacional. O Japão, mesmo não participando oficialmente das exposições que ocorriam na Europa, começa a atrair cada vez mais admiradores de seus objetos de laca, porcelanas e makie. Uma das principais exposições de peças nipônicas no Ocidente ocorreu em 1862, na Segunda Exposição Internacional, em Londres. As peças nipônicas dessa exposição internacional pertenciam, em sua maioria, ao primeiro ministro britânico sir Rutherford Alcock que colecionou muitas peças artísticas japonesas durante sua 
estada no Japão e chegou a publicar várias obras a respeito da arte nipônica. Após a exposição, algumas peças japonesas foram adquiridas pelo Museu de Arte Ornamental de Londres. Esse evento foi a pedra-de-toque que tornou popular, entre os intelectuais, a tão longínqua arte japonesa.

Foi somente em 1867, no final da era Tokugawa, que o Japão participou oficialmente de uma exposição internacional que ocorreu em Paris. Inúmeros produtos foram selecionados e enviados a Paris, desde ferramentas agrícolas, espadas, instrumentos musicais, até pequenos barcos. A partir daí, Paris descobriu rapidamente o mundo artístico japonês. Nesse período foi aberto o Oriental Art Shop La Porte Chinoise em Paris e que foi freqüentado por intelectuais e artistas como Baudelaire, Edmond Goncourt, Jules Goncourt, Monet e James Mc Whistler.

Em 1873, ocorreu uma outra exposição internacional, desta vez em Viena. Nessa época, o Japão já havia reatado as relações comerciais com os países do Ocidente e estava em pleno processo de modernização, razão pela qual sua participação teve interesses mais políticos de divulgação e auto-promoção, do que artístico e cultural.

O Japão ainda participou das seguintes exposições:

1876 - Exposição em Filadélfia;

1878 - Exposição Internacional em Paris, quando Matsukata Masayoshi constrói um jardim japonês;

1886 - Exposição Internacional em Londres;

1889 - Exposição Internacional em Paris;

1893 - Exposição Mundial em Chicago;

1894 - Exposição em São Francisco;

1897 - Exposição Internacional em Bruxelas;

1900 - Exposição Internacional em Paris.

A partir da exposição de 1867 até 1878, o fenômeno conhecido como Japonismo ganhou dimensão e destaque, principalmente entre os pintores impressionistas ${ }^{2}$, dentre eles, Degas, que retomou alguns temas femininos e adotou a composição oblíqua, e Van Gogh, que copiou paisagens de pinturas japonesas, como A Chuva de Hiroshigue. Mas, a figura que mais mergulhou no mundo artístico japonês foi Claude Monet (18401926).

Esse pintor revolucionário desprezou a pintura em estúdio e procurou, diretamente na natureza, os "motivos" de suas obras, os quais foram registrados com pinceladas rápidas e pouco acabamento, devido o seu aspecto efêmero, de mudança constante sob os efeitos de luz e condições climáticas. Assim sendo, Monet preocupou-se mais com o efeito geral do todo, do que com os detalhes. E foi essa abordagem aparentemente descuidada que incomodou os críticos e os gostos tradicionais que estavam acostumados com "temas dignos" e "composições equilibradas" Na verdade, para alguns críticos de arte como Arnold Hauser, o impressionismo vive o momento das rápidas transformações

1. Na época, os europeus não faziam distinção entre os termos chinês e japonês.

2. Impressionismo designa uma escola de pintura que se desenvolveu na França durante a segunda metade do século XIX 
citadinas, daí o seu estilo urbano que descreve a mutabilidade, o ritmo nervoso, as impressões súbitas, pungentes, mas sempre efêmeras da vida das cidades ${ }^{3}$.

Apesar dos percalços iniciais, o impressionismo consolidou-se como uma arte séria e uma inovação no campo das técnicas de pintura. Um dos aliados dos impressionistas, nessa luta em busca de novos motivos e novos esquemas de cor, foi a cromotipia japonesa que ainda não havia sido contaminada pelas convenções tradicionais européias. Aliás, os japoneses possuem tradicionalmente um senso estético monocromático. Eles apreciam o efeito de neutralidade, por essa razão a cor preta é utilizada para acentuar a silhueta e dar um ar de sobriedade.

As xilogravuras japonesas ajudaram os pintores impressionistas a eliminarem alguns resquícios das convenções tradicionais que ainda persistiam em suas obras. Os principais mestres japoneses foram Hokusai (1760-1849) e Utamaro (1753-1806) que lançaram, sobre os impressionistas, sugestões de arte não-convencional. É o que podemos notar na pintura do Monte Fuji Visto atrás de um Poço, de Hokusai. Na realidade, nem o Monte Fuji, tampouco o poço é a parte relevante da estampa, pois não há a preocupação da pintura em mostrar sempre o todo ou uma parte relevante de cada cena ou figura.

Sem dúvida, essas estampas japonesas tiveram o seu papel de destaque na pintura européia. Entretanto, muito antes do fenômeno do Japonismo espalhar-se entre os intelectuais e artistas europeus, Claude Monet já apreciava as xilogravuras nipônicas. Há muitas versões acerca do início do contato entre o pintor francês e as estampas japonesas, mas de acordo com algumas biografias, Monet não as conheceu em 1866, quando esteve na Holanda. Na realidade, a descoberta ocorreu por um acaso em 1856 em Havre, numa loja de curiosidades. Desde então, Monet foi seduzido pelos efeitos da bruma, de claridade e de transparência das sombras das gravuras japonesas.

A utilização dos elementos nipônicos era consciente em Monet que possuía um vasto acervo sobre a cultura japonesa em sua biblioteca particular, fato que contribuiu para enriquecer a sua visão plástica.

Outra fonte da arte japonesa que Monet possuía era sua amizade com um comerciante japonês que se estabeleceu em Paris por conta própria, Hayashi Tadamasa. Admirador de obras impressionistas, Tadamasa negociou com Monet estampas japonesas de Utamaro, Eishi e Hokusai, em troca das obras do artista francês. Esse intercâmbio foi fundamental para a entrada da pintura francesa, especialmente as de Monet no Japão, pois em 1893, Tadamasa expôs, pela primeira vez em Tóquio, algumas pinturas impressionistas. Homem de vasta cultura artística, participou da organização de duas exposições em Paris e escreveu a obra História da Arte do Japão, em 1900.

Amigos franceses também enriqueceram a visão de Monet sobre o Japão. Gustave Geffroy, que foi fascinado pela pintura oriental e escreveu vários artigos e críticas sobre a pintura japonesa, e Theódore Duret que também possuía um bom conhecimento acerca da cultura japonesa, e que visitou o Japão em 1863 e 1871.

Inicialmente, Monet apenas inseria os elementos nipônicos em suas obras conservando o estilo ocidental de pintura, chegando a ser até mesmo acadêmico, como

3. Arnold Hauser, História Social da Arte, p. 1049 
é o caso de A Moça Japonesa, 1876, ou seja, embora esses elementos fossem visíveis, não estavam ainda totalmente assimilados pelo pintor. Entretanto, à medida que seus conhecimentos sobre a arte e a cultura japonesa foram se aprofundando, os elementos visíveis foram desaparecendo, dando lugar às sutilezas das técnicas e dos "motivos"

Num primeiro lance, não detectamos nenhuma "influência" da pintura japonesa sobre as obras de Monet, porém, ao compararmos com as suas "fontes" nipônicas, somos obrigados a reconhecer certas "analogias" Se partirmos do pressuposto de que comparar é ver semelhanças e diferenças, podemos afirmar que há "parentescos" e "influências" entre as obras francesas e japonesas, no entanto, um olhar mais crítico buscará as diferenças dentro das analogias, assimilações e transformações. A partir do momento que Monet entrou em contato com as gravuras japonesas, essas obras sofreram um processo de recepção e, conseqüentemente, transformação.

Um exemplo clássico da assimilação da arte e da cultura japonesa expressa por Monet seria o Jardim Japonês, que é considerado, por alguns críticos, a síntese do Oriente com o Ocidente. Claude Monet, após se mudar para Giverny, resolve construir um jardim japonês, ao lado de seu jardim em estilo ocidental. Todos os detalhes foram cuidadosamente administrados, desde a jardinagem e a construção da ponte, até a canalização de um braço do rio Epte para a formação do lago.

Percorrendo a história do Japão, constatamos que o jardim japonês possui uma origem ligada à divindade, mais precisamente à religião Shintoísta que venera os elementos da natureza e costuma erguer seus santuários nos yu-niwa (jardins de veneração). $O$ jardim japonês também teve seu destaque nos grandes cenários da literatura e da arte nipônica. Na obra Man'yôsh japonesa e que foi compilada no século VIII - os jardins têm seu papel de destaque nos cenários. Já em Genji Monogatari, outro clássico da literatura japonesa redigida no século X pela dama da Corte Murassaki Shikibu, os jardins são minuciosamente detalhados para descrever a vida palaciana dos nobres da época, em particular, as aventuras amorosas do Príncipe Genji. Na realidade, os jardins representavam muito mais do que um simples cenário decorativo, pois os nobres daquela época costumavam contemplar a beleza da natureza nos jardins do palácio para atingirem o mono no aware, ou seja, as emoções das coisas fugazes. Coincidentemente, o impressionismo também busca, de uma certa forma, esse momento fugaz.

\section{Bibliografia}

ADAMS, Steven. The World of the Impressionists. London, Thames, 1989.

GORDON, Robert. Monet. New York, Abrams, 1989.

HAUSER, Arnold. História da Literatura e da Arte. Tradução de Walter H. Geenen. 2a ed., São

Paulo, Mestre Jou, 1972.

HOUSE, John. Monet: nature into art. 5a ed., New Haven, Yale University Press, 1986.

KIDDER, J. Edward. El arte del Japon. Madrid, Ediciones Catedra, 1985.

LEE, Sherman E. L'art oriental. Paris, Sequoia, 1966.

MINSTERBERG, Hugo. The art of Japan: an illustrated history. Tokyo, Tuttle, 1983.

NomA, Seiroku. Japanese sense of beauty. Tokyo, Asahi Shimbun Publishing, 1963. 
The art of Japan. Translated by Glenn T. Webb. Tokyo, Kondansha Internacional, 1980.

OKaDA, Jô. Museu Nacional de Tóquio. São Paulo, Melhoramentos, 1968.

REWALD, John. História do Impressionismo. Tradução de Jefferson Luís Camargo. São Paulo, Martins Fontes, 1991.

Endereço para correspondência:

Universidade Estadual Paulista - UNESP (Campus de Assis)

Departamento de Letras Modernas

Área de Língua e Literatura Japonesa

Av. Dom Antônio, 2100

19800-000 - Assis - SP 